\title{
Métodos que visam prevenir a transmissão vertical do HIV em mães soropositivas: revisão integrativa
}

\author{
Methods aimed at preventing vertical transmission of HIV in HIV-positive mothers: an \\ integrative review
}
Métodos destinados a prevenir la transmisión vertical del VIH en madres seropositivas: una revisión integradora

Nayara Luiza da Silva Oliveira Martins ${ }^{1 *}$, Lenice Pereira de Amorim ${ }^{1}$, Ana Cristina Gaspar de Cerqueira ${ }^{1}$, Yonaira Araújo Marques ${ }^{1}$, Marco Aurélio Ninômia Passos².

\section{RESUMO}

Objetivo: Descrever os métodos e procedimentos que podem ser aplicados pelos profissionais de enfermagem, visando prevenir a transmissão vertical do Vírus da Imunodeficiência Humana (HIV), em mães soropositivas. Métodos: $O$ presente trabalho foi realizado através de um estudo de revisão da literatura, do tipo integrativa entre 2016 e 2021, com posterior análise descritiva das informações obtidas. Esse método de pesquisa é um dos mais utilizados no âmbito da Prática Baseada em Evidências (PBE). Biblioteca Virtual em Saúde (BVS), Base de Dados de Enfermagem (BDENF), Literatura Latino-Americana e do Caribe em Ciências da Saúde (LILACS) e Scientific Electronic Library Online (SCIELO) foram utilizadas como banco de dados para a busca de artigos disponíveis na íntegra. Resultados: 10 artigos científicos foram selecionados e revisados com o intuito de se obter um conjunto de ideias e conhecimentos sobre as suas discussões, para obtermos uma resposta para a nossa pergunta norteadora. Considerações finais: Observa-se que os métodos e procedimentos adotados pelos enf ermeiros são essenciais e imprescindíveis para a prevenção da Transmissão Vertical (TV) do HIV. Também pode-se perceber que ainda existem muitos obstáculos a serem enfrentados e discutidos nesse caminho para serem quebradas e discutidas sobre essas ações para que se obtenha uma atenção à saúde de qualidade.

Palavras-chave: Gestação, Transmissão vertical do HIV, Prevenção da transmissão vertical.

\section{ABSTRACT}

Objective: To describe the methods and procedures that can be applied by nursing professionals in order to prevent vertical transmission of the Human Immunodeficiency Virus (HIV) in HIV-positive mothers. Methods: The present work was carried out through an integrative literature review study between 2016 and 2021, with subsequent descriptive analysis of the information obtained. This research method is one of the most used in the scope of Evidence-Based Practice (EBP). Virtual Health Library (VHL), Nursing Database (BDENF), Latin American and Caribbean Literature on Health Sciences (LILACS) and Scientific Electronic Library Online (SCIELO) were used as a database to search for articles available in full. Results: 10 scientific articles were selected and reviewed in order to obtain a set of ideas and knowledge about their discussions, in order to obtain an answer to our guiding question. Final considerations: It is observed that the methods and procedures adopted by nurses are essential and essential for the prevention of Vertical Transmission (VT) of HIV. It can also be seen that there are still many obstacles to be faced and discussed in this way to be broken and discussed about these actions in order to obtain quality health care.

Key words: Pregnancy, Vertical transmission of HIV, Prevention of vertical transmission.

\footnotetext{
1 Universidade Paulista (UNIP), Brasília - DF. *E-mail: nay22silva@gmail.com

2 Universidade de Brasília (UNB), Brasília - DF.
} 


\section{RESUMEN}

Objetivo: Describir los métodos y procedimientos que pueden ser aplicados por profesionales de enfermería para prevenir la transmisión vertical del Virus de Inmunodeficiencia Humana (VIH) en madres VIH positivas. Métodos: El presente trabajo se realizó a través de un estudio integrador de revisión de literatura entre 2016 y 2021, con posterior análisis descriptivo de la información obtenida. Este método de investigación es uno de los más utilizados en el ámbito de la Práctica Basada en la Evidencia (PBE). La Biblioteca Virtual en Salud (BVS), la Base de Datos de Enfermería (BDENF), la Literatura Latinoamericana y del Caribe en Ciencias de la Salud (LILACS) y la Biblioteca Científica Electrónica en Línea (SCIELO) se utilizaron como base de datos para la búsqueda de artículos disponibles en su totalidad. Resultados: Se seleccionaron y revisaron 10 artículos científicos con el fin de obtener un conjunto de ideas y conocimientos sobre sus discusiones, con el fin de obtener una respuesta a nuestra pregunta guía. Consideraciones finales: Se observaque los métodos y procedimientos adoptados por los enfermeros son fundamentales y esenciales para la prevención de la Transmisión Vertical (TV) del VIH. También se puede ver que todavía hay muchos obstáculos que enfrentar y discutir de esta manera para romper y discutir sobre estas acciones para obtener una atención de salud de calidad.

Palabras clave: Embarazo, Transmisión vertical del VIH, Prevención de la transmisión vertical.

\section{INTRODUÇÃO}

No Brasil, entre 2009 e 2019 houve um aumento de cerca de 21,7\% na taxa de detecção de gestantes infectadas pelo Vírus da Imunodeficiência Humana (HIV). Isso pode ser explicado pela observação da taxa de detecção do HIV por faixa etária e sexo, que compreende mulheres entre 20 e 39 anos, representando $57 \%$ do total de casos, faixa etária que corresponde ao período mais fértil dessas mulheres. Por essa razão, se faz necessário enfatizar a importância dos procedimentos que visam prevenir a transmissão vertical do vírus. Pois, mesmo a Transmissão Vertical do HIV (TV - HIV) sendo uma doença de caráter evitável, ainda é tida como problema de saúde pública no Brasil (BRASIL, 2020).

A forma de transmissão vertical do HIV acontece quando há disseminação do vírus da mãe para o filho durante a gravidez, no parto por haver contato com os líquidos do cérvice vaginal e sangue da mãe, e durante a amamentação. Alguns fatores podem contribuir para a diminuição dos índices da TV - HIV e estes vão de encontro à universalidade e equidade de acesso ao tratamento, demonstrando assim, que determinadas populações têm maior necessidade de educação em saúde e planejamento familiar na linha de cuidado à prevenção ao HIV (SILVA SS, et al., 2015).

Para Macêdo VC (2009), outros fatores que contribuem para o crescimento da TV no Brasil é a falta de articulação entre os serviços de atendimento à gestante com HIV, falhas na testagem para investigar HIV, falta de ampliação dos programas de prevenção de Infecções Sexualmente Transmissíveis (IST) e orientações inadequadas ou inexistentes no pré-natal, se tais aspectos fossem modificados o atual panorama seria melhorado, aumentando o número de crianças que teriam acesso à profilaxia da TV - HIV. Sendo que, para atingir a eliminação completa da TV é necessário entender os determinantes de riscos relacionados à transmissão do HIV.

Ao decorrer da gestação, a TV de doenças infecciosas de uma mãe infectada para o feto pode levar a consequências devastadoras no desenvolvimento da criança. A TV pode ser pré-natal (antes do nascimento), perinatal (durante o parto ou imediatamente após), ou pós-natal (após o nascimento). A infecção fetal prénatal é a principal causa de morbidade e mortalidade a nível global (ARORA N, et al., 2017).

Há muitos investimentos que impulsionam a realização de projetos, programas e campanhas que visam diminuir a TV do HIV, mas a eliminação desse agravo continua sendo um desafio para as políticas públicas de saúde do Brasil, sendo um dos países que não atingiram a meta de redução da TV do HIV para números menores que dois casos a cada 100 mães infectadas, conforme foi estabelecido pela Organização PanAmericana de Saúde (OPAS) e Organização Mundial de Saúde (OMS). A taxa de detecção de AIDS em 
crianças menores de cinco anos é utilizada como um indicador indireto no monitoramento da transmissão vertical do HIV no país.

Com isso, pode-se observar que houve uma queda nesse número, cerca de $47,2 \%$ de redução, sendo em 2009 o número registrado de 3,6 casos/100 mil habitantes, para 1,9 casos/100 mil habitantes no ano de 2019. Porém, o que se pode evidenciar é que no Brasil, essa taxa utilizada como indicador não se apresenta de forma homogênea pelo país, mas sim de forma heterogênea, onde há lugares com taxas elevadas e outros locais com taxas reduzidas (OMS, 2019).

A equipe de enfermagem tem grande importância na orientação das gestantes, já que estas possuem necessidades diferenciadas, devendo ser bem compreendidas pela equipe, tais fatores fazem com que estas mulheres tenham a necessidade de serem acolhidas e tratadas adequadamente. A enfermagem pode realizar a notificação da infecção pelo HIV das gestantes e crianças expostas ao risco da transmissão vertical. Essa notificação deve ser realizada por meio da Ficha de Notificação Individual (FIN) e enviada semanalmente à secretaria de saúde pelo sistema. Nestes casos, a cada gestação de mulher infectada pelo HIV, uma nova notificação de gestante por HIV é realizada (BICK MA, et al., 2018).

As intervenções e métodos dos profissionais de saúde têm como foco a atuação da equipe de enfermagem e, se executados corretamente, podem ser aplicados de acordo com as diretrizes do Ministério da Saúde, principalmente durante e logo após o pré-natal. O período do parto e pós-parto, incluindo a amamentação, pode reduzir o risco de TV de até $45 \%$ para menos de $2 \%$. Se a mãe continuar a receber terapia antirretroviral, pode até ser inferior a 1\% (VASCONCELOS CS, et al., 2021).

Nesse contexto, temos o papel do enfermeiro em destaque, pois segundo Gonçalves TR, et al. (2020), o mesmo é responsável pela assistência direta à gestante e durante o pré-natal é essencial a orientação da mesma sobre ações de saúde educativas para que ocorra uma gestação sem a presença de agravos, com isso há um maior monitoramento pela própria gestante acerca dos fatores relacionados à prevenção do TV do HIV.

Com isso, o presente trabalho teve como objetivo descrever os métodos e procedimentos que podem ser aplicados pelos profissionais de enfermagem, visando prevenir a transmissão vertical do HIV, em mães soropositivas.

\section{MÉTODOS}

O presente trabalho foi realizado através de um estudo de revisão da literatura, do tipo integrativa, com posterior análise descritiva das informações obtidas. Esse método de pesquisa é um dos mais utilizado no âmbito Prática Baseada em Evidências ( $P B E$ ), pois é um método de pesquisa que permite construir conhecimento em saúde, gerando, um saber bem estruturado e uniforme, permitindo que todos os profissionais da área, com ênfase para os profissionais de enfermagem, posam realizar uma prática clínica de qualidade (GONÇALVES, 2019).

Sendo assim essa pesquisa foi realizada a partir de uma revisão da integrativa da literatura, de caráter descritivo, onde tentou responder a seguinte pergunta norteadora: Quais os métodos que podem ser empregados pelos profissionais de enfermagem que visam prevenir a transmissão vertical do HIV em gestantes soropositivas?.

A busca por artigos científicos foi realizada na Biblioteca Virtual em Saúde (BVS), Base de Dados de Enfermagem (BDENF), Literatura Latino-Americana e do Caribe em Ciências da Saúde (LILACS) e Scientific Electronic Library Online (SCIELO). O site oficial do Ministério da Saúde foi consultado na busca de Protocolos Clínicos e Diretrizes Terapêuticas mais recentes, relacionados à prevenção da Transmissão vertical do HIV. A seleção dos descritores e palavras-chave utilizados no processo de revisão foi ef etuada mediante consulta aos Descritores em Ciência da Saúde (DeCS), sendo escolhidos: "Complicações Infecciosas na Gravidez", "Transmissão Vertical de Doenças Infecciosas/prevenção \& controle", "Infecções por HIV", "gravidez" e "Infecções porHIV/prevenção \& controle". As palavras -chave utilizadas no Banco de dados da SCIELO foram: Transmissão vertical do HIV, com artigos publicados a partir de 2016. 
Foram utilizadas como critérios de inclusão as literaturas publicadas a partir do ano de 2016, em inglês ou português e com assunto pertinente ao tema. Os critérios de exclusão, além dos já citados, foram a leitura do resumo dos artigos que não apresentava relação com o tema proposto.

Com a aplicação dos descritores nos bancos de dados, foram encontrados 371 artigos na Bireme e 28 artigos na SCIELO. Totalizando 399, que passaram por uma leitura dos seus títulos e resumos, sendo descartados os que não havia envolvimento com o trabalho proposto. Posteriormente, foram selecionados 45 entre os artigos para serem lidos na íntegra, os artigos que cumpriam com os critérios da pesquisa, foram selecionados, compreendendo um total de 10 artigos. A Figura 1 descreve os procedimentos adotados para a seleção dos artigos a partir de um fluxograma.

Figura 1 - Fluxograma do método de seleção dos artigos.

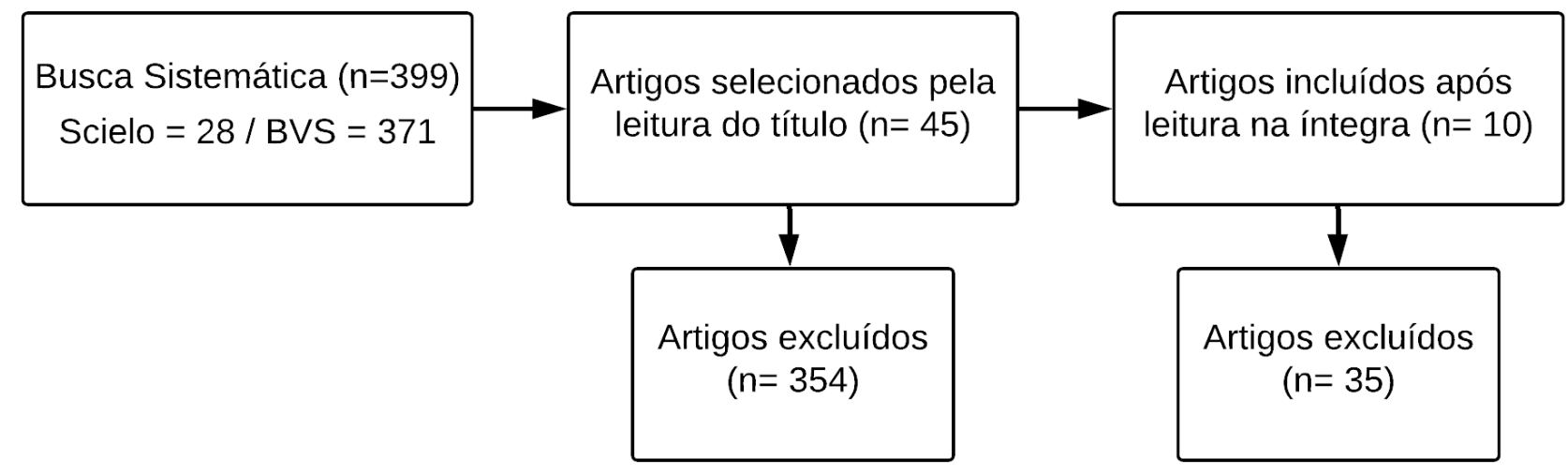

Fonte: Martins NL, et al., 2021.

\section{RESULTADOS}

Após a execução da metodologia proposta para a pesquisa, seguiu-se para a filtragem de estudos que abordassem o tema de maneira clara e coerente, objetivando que o leitor entedesse a relevância do tema para a área da saúde, sendo assim, foram selecionados 10 artigos apresentados no quadro 1 que contribuem para o embasamento da discussão. Conforme exposto abaixo dos 10 artigos selecionados 4 fazem relação do HIV com questões socioeconomicas, 3 avaliam a ef etividade das estratégias de prevenção , 1 traça o perfil o clínico da patologia, 1 expõe as medidas preventivas e 1 detalha a educação como ferramenta para promoção da saúde (Quadro 1). 
Quadro 1 - Agrupamento dos artigos, segundo o autor(es), ano de publicação, proposta(s), e principais achados.

\begin{tabular}{|c|c|c|}
\hline Autores (Ano) & Proposta & Principais achados \\
\hline Silva SS, et al. (2015). & $\begin{array}{l}\text { Analisar por meio do acervo literário o cenário social em que } \\
\text { a mulher com HIV está sujeita a viver, investigando os } \\
\text { aspectos que as levam a aderirem ou não o tratamento } \\
\text { preventivo da transmissão vertical. }\end{array}$ & $\begin{array}{l}\text { A análise evidenciou que a rede de apoio a gestante com HIV é } \\
\text { essencial para prevenir a Transmissão Vertical (TV), e que há um } \\
\text { déficit de multiprofissionais e isso contribui para a não adesão ao } \\
\text { tratamento, além do que a atuação do enfermeiro transcende os } \\
\text { cuidados biológicos percutindo às práticas orientativas e suporte } \\
\text { emocional. }\end{array}$ \\
\hline Gonçalves TR, et al. (2020). & $\begin{array}{l}\text { Observar os procedimentos preventivos que abrangem as } \\
\text { mulheres em situação vulnerável, entendendo como elas } \\
\text { podem ser incluídas de acordo com seu estado individual, } \\
\text { social, biomédico, psicossocial e entendimento sobre o HIV. }\end{array}$ & $\begin{array}{l}\text { O procedimento observacional constatou que a maioria das } \\
\text { mulheres se incluíram na vulnerabilidade individual, sugerindo a } \\
\text { necessidade de fortificar as estratégias preventivas no sentindo das } \\
\text { vulnerabilidades. }\end{array}$ \\
\hline Fernandes RC, et al. (2005). & $\begin{array}{l}\text { Estudar as variáveis que contribuem para as ações de } \\
\text { prevenção do HIV, como a idade materna, a época de } \\
\text { descoberta do HIV, o nível de escolaridade, acesso à } \\
\text { informação sobre as Infecções Sexualmente Transmissíveis } \\
\text { (IST), tipo do parto, o momento de ruptura das membranas, } \\
\text { peso ao nascer, no município de Campos Goytacazes do } \\
\text { estado do Rio de Janeiro. }\end{array}$ & $\begin{array}{l}\text { O estudo demonstrou que as gestantes que tiveram acesso às } \\
\text { informações e fizeram o teste de HIV no pré-natal tiveram um } \\
\text { resultado benéfico na diminuição da transmissão perinatal do HIV. }\end{array}$ \\
\hline Miranda AE, et al. (2016). & $\begin{array}{l}\text { Avaliar as estratégias de prevenção que reduzem a } \\
\text { transmissão vertical do HIV, com base nos dados dispostos } \\
\text { no Sistema de Informação de Agravos de Notificação } \\
\text { (SINAN), nos seguintes estados: Distrito Federal, Rio de } \\
\text { Janeiro, Rio Grande do Sul, Ceará e Amazonas. }\end{array}$ & $\begin{array}{l}\text { As estratégias de prevenção apresentam falhas, e é necessário que } \\
\text { a atenção básica e os centros de referência de HIV estejam } \\
\text { integrados para orientar o cuidado familiar gerando um desfecho de } \\
\text { promoção à saúde para a criança. }\end{array}$ \\
\hline Macêdo VC, et al. (2009). & $\begin{array}{l}\text { Investigar se as assistências prestadas de acordo com as } \\
\text { intervenções de o projeto nascer às gestantes de quatro } \\
\text { maternidades da rede pública do nordeste do Brasil estão } \\
\text { sendo eficazes na prevenção do HIV vertical. }\end{array}$ & $\begin{array}{l}\text { O estudo apontou que é necessário o desenvolvimento de ações que } \\
\text { se articulem tanto com a gestão em saúde, como com os gerentes } \\
\text { das respectivas unidades e profissionais da saúde, pois assim a } \\
\text { situação TP será revertida no Brasil. }\end{array}$ \\
\hline Bick MA, et al. (2018). & $\begin{array}{l}\text { Caracterizar o perfil clínico das gestantes de um município } \\
\text { do interior do Rio Grande do Sul, com base nos aspectos } \\
\text { clínicos e sociais de transmissibilidade vertical do HIV. }\end{array}$ & $\begin{array}{l}\text { O perfil caracterizado com maior predisposição para a TV do estudo } \\
\text { foi às mulheres que estavam em situação socialmente desfavorável. }\end{array}$ \\
\hline
\end{tabular}




\begin{tabular}{|c|l|l|}
\hline Autores (Ano) & \multicolumn{1}{|c|}{ Proposta } & \multicolumn{1}{|c|}{ Principais achados } \\
\hline Lanal FC e Lima AS (2010). & $\begin{array}{l}\text { Constatar se o pré-natal realizado na rede pública de saúde } \\
\text { do Distrito Leste do município de Belo Horizonte é eficiente } \\
\text { para a prevenção vertical do HIV. }\end{array}$ & $\begin{array}{l}\text { O estudo constatou que existem algumas barreiras que impedem } \\
\text { e/ou dificultam o alcance do pré-natal de qualidade na região } \\
\text { analisada. Sendo o índice de crescimento das gestantes que } \\
\text { realizam pelo menos as } 6 \text { consultas baixo, captação precoce } \\
\text { deficitária, número ineficaz das mulheres grávidas que realizam o } \\
\text { teste anti HIV. }\end{array}$ \\
\hline Trindade LN, et al. (2020). & $\begin{array}{l}\text { Apresentar a epidemiologia do HIV nas gestantes, } \\
\text { apontando os fatores que contribuem para a disseminação } \\
\text { da TV. }\end{array}$ & $\begin{array}{l}\text { O perfil epidemiológico de TV do HIV nas gestantes observadas no } \\
\text { estudo tem relação com o nível de escolaridade, cor, ocupação, } \\
\text { utilização da terapia antirretroviral (TARV), adesão ao pré-natal e } \\
\text { tipo de parto. }\end{array}$ \\
\hline Vasconcelos CS, et al. & \multicolumn{1}{|c|}{$\begin{array}{l}\text { As medidas expostas para prevenção da TV - HIV foram embasadas } \\
\text { de acordo com o que estabelece o Ministério da Saúde, sendo } \\
\text { necessário realizar a testagem de HIV no primeiro e terceiro } \\
\text { trimestre de gestação durante o pré-natal, utilizar o método } \\
\text { terapêutico antirretroviral em três momentos que correspondem aos } \\
\text { períodos de antes e durante a gestação e no nascimento do bebê. }\end{array}$} \\
\hline Lima AC, et al. (2018). & $\begin{array}{l}\text { Evidenciar como os aspectos tecnológicos podem contribuir } \\
\text { coma educação em saúde no intuito de prevenir a TV - HIV. }\end{array}$ & $\begin{array}{l}\text { As práticas educacionais aliadas às ferramentas tecnológicas } \\
\text { podem promover saúde no sentido da TV-HIV, porém ainda é } \\
\text { necessário que os profissionais enfermeiros se atualizem } \\
\text { continuamente sobre os métodos educacionais em saúde. }\end{array}$ \\
\hline
\end{tabular}

Fonte: Martins NL, et al., 2021. 


\section{DISCUSSÃO}

A fim de compreender os métodos que contribuem para a prevenção da transmissão vertical do HIV em mães soropositivas, surge uma discussão que vai de encontro às questões sociais, conforme o que demonstra o autor Silva SS, et al. (2015), que relaciona o cenário social no qual a mulher vive com a adoção dos métodos de tratamento para prevenir a TV. Essas questões se referem ao nível baixo de escolaridade, pobreza, feminilização, falta de rede de apoio primária que inclui a família, colegas e equipe de trabalho, e secundária que são os profissionais da saúde, tais fatores fazem com que as mulheres abandonem a profilaxia da TV, ou até mesmo nem iniciem o tratamento.

Para Gonçalves TR, et al. (2020), é necessário que as mulheres grávidas com HIV recebam tratamento e tenham um suporte de acordo com suas particularidades, já que no grupo feminino a prevalência do HIV está ligada a especificidade da situação vulnerável em que se encontram, além da associação à questões de relacionamento com o cônjuge, pois grande parte dessa população depende economicamente do parceiro, e estão ligadas a títulos e pensamentos preconceituosos e arcaicos em relação a maternidade, estudos e trabalho levando ao não acesso às informações que poderiam prevenir a disseminação do HIV e outras IST.

Ainda em relação ao HIV atrelado as questão sociais Fernandes RC (2005), Trindade LN, et al. (2020), trazem à tona que o acesso a informação e atendimento de qualidade na rede de atenção primária implicam na redução da TV, pois essas mulheres em situação de vulnerabilidade muitas vezes não tem em sua região demográfica uma unidade básica de saúde e centros de referência do HIV com enfermeiros capacitados, sendo assim, se elas tivessem acesso a um atendimento dentro do princípio da equidade, que de acordo com o Sistema Único de Saúde (SUS), o indivíduo deve ser tratado segundo sua necessidade, tais mulheres teriam as devidas orientações para o tratamento, contribuindo para não ocorrer a verticalização do HIV, pois elas seriam constantemente acompanhadas e motivadas a permanecerem no tratamento.

De acordo com Miranda AE, et al. (2016), em seu estudo houve um representativo de quase $20 \%$ de mulheres no estado do Amazonas que chegaram ao parto sem ter conhecimento de que eram soropositivas, e $29 \%$ sequer fizeram o teste de HIV no pré-natal, isso demonstra um alto índice de TV ligado ao pré-natal ineficaz, além da falta de importância que os profissionais da saúde tem em relação ao Sistema de Informações de Agravos de Notificação (SINAN), dado que é durante o pré-natal que a mulher é acolhida, amparada, submetida a exames, teste Anti-HIV e inserida em ações educativas visando a promoção, prevenção e detecção de doenças. E levando em consideração o rastreamento da doença de acordo com o relato do autor, o SINAN garante o controle da patologia por meio da inserção dos dados das mulheres com diagnóstico de Síndrome da Imunodeficiência Adquirida (AIDS) ajudando a estabelecer as melhores estratégias nas esferas federal, estadual e municipal.

Apesar de tais falhas, o método de prevenção da TV - HIV é satisfatório quando aplicado com coerência, preocupação, acolhimento, humanização e equidade de gênero dentro das necessidades de cada gestante, com olhar integral e amplo, sendo consideradas como medidas preventivas de acordo com Brasil (2020), o teste para HIV e demais IST durante o pré-natal, a utilização da terapia antirretroviral profilática antes, ao decorrer da gestação e no nascimento do bebê, o parto deve ser do tip o cesáreo para a mulher com Carga Viral (CV) de HIV desconhecida ou superior a 1.000 cópias/ml, o leite materno deve ser substituído porfórmula láctea, o recém-nascido deve usar zidovudina e outros fármacos para prevenir a pneumonia, além da obrigatoriedade da notificação de todos os casos no SINAN.

Destacando a questão do teste de HIV Vasconcelos CS, et al. (2021), evidencia que deve ser feito na primeira consulta de pré-natal que por recomendação do Ministério da Saúde o ideal é acontecer no primeiro trimestre de gravidez, sendo repetido no terceiro trimestre e no momento do parto, independentemente dos resultados de testes anteriores, pois a testagem é uma ferramenta essencial no método de prevenção vertical. No pré-natal há também a investigação se a gravidez foi planejada ou não, se planejada as intervenções podem ser feitas de maneira adequada durante o parto e amamentação, desta forma o risco de TV - HIV é reduzido a um percentual menor que $2 \%$ e se não houver o planejamento correto com continuidade o risco é aumentado de $15 \%$ a $45 \%$. 
Para Brasil (2020), no planejamento familiar a orientação para a Profilaxia Pré-Exposição (PrEP) será definida dependendo se a parceria vive com HIV antes do início do período fértil, pois a primeira dose a ser tomada vai depender da via sexual, se for vaginal será necessário menos de 20 dias. Quando a PrEP é iniciada no primeiro dia da menstruação há garantia maximizada de proteção, considerando o comportamento humano e farmacocinética durante o período fértil.

Ainda de acordo com Brasil (2020), quando a mulher engravidar deverá haver uma avaliação da continuidade da PrEP, a mesma deve ser orientada quanto ao uso de preservativo. O período de puerpério e aleitamento materno também requer atenção e deve ser ofertado à testagem para HIV, pois durante esses momentos há um grande número de casos de infecção aguda pelo HIV. O teste laboratorial deverá ser empregado dependendo da agilidade da entrega do resultado já que o objetivo é prevenir a TV e isso depende do tempo oportuno.

Alguns casos Lanal FC e Lima AS (2010), como transfusão sanguínea, doenças autoimunes, hemodiálise, múltiplos partos e vacinação recente requerem um olhar especial quanto a eficácia do teste de HIV que raramente pode dar um resultado falso-negativo, mas nessas situações devem ser observados. Deste modo a coleta da CV - HIV terá quer ser executada em qualquer fluxo diagnóstico, de imediato e antes da iniciação da Terapia Antirretroviral (TARV). A genotipagem é recomendada para todas as grávidas que forem iniciar a TARV, porém não é necessário esperar o resultado dela para começar o tratamento antirretroviral.

As intervenções e métodos que os profissionais de saúde, enfatizando a equipe de enfermagem, podem aplicar são baseados nas diretrizes do Ministério da Saúde, e como exposto, se forem realizadas de forma adequada e durante o pré-natal, parto e aleitamento materno, que segundo Lima ACMAC, et al. (2018), podem reduzir o risco de ocorrer à transmissão vertical de até $45 \%$ para menos de $2 \%$, podendo ainda ser menor que $1 \%$ se a mãe continuar com a terapia antirretroviral, considerando-se assim, os enfermeiros como peçachave no controle e diminuição da TV-HIV.

\section{CONSIDERAÇÕES FINAIS}

Foi possível observar que o método preventivo da transmissão vertical que tem maior destaque é o teste para detecção do HIV, pois ele será o divisor de águas para iniciar e manter o tratamento, seguido das orientações à gestante. Destaca-se também o papel do enfermeiro no pré-natal, não só na realização do mesmo, mas na preocupação em inserir cada mulher segundo sua necessidade social, vulnerabilidade econômica, demográfica e demais aspectos epidemiológicos que por vezes incluem a cor, raça, etnia, estado civil e nível de escolaridade. É fundamental a adoção do método de educação em saúde por parte da equipe de enfermagem em prol da divulgação de informações. A captação de gestantes de forma humanizada e integral fará com que elas tenham maior adesão à unidade de atenção primária, articulando o cuidar com os demais serviços que prestam apoio a gestante com HIV, resultando assim, na promoção à saúde dos binômios mãe e filho.

\section{REFERÊNCIAS}

1. ARORA N, et al. Microbial vertical transmission during human pregnancy. Cell Host Microbe. Revista PubMed, 2017; 21(5): 561-567.

2. BICK M, et al. Perfil de gestantes infectadas e crianças expostas ao HIV atendidas em serviço especializado do sul do Brasil. Revista Brasileira de Saúde Materno Infantil, 2018; 18 (4): 803-813.

3. BRASIL. Boletim epidemiológico HIV/AIDS. 2020. Disponível em: http://www.aids.gov.br/pt-br/pub/2020/boletimepidemiologico-hivaids-2020. Acessado em:29 de outubro de 2021.

4. BRASIL. Manual técnico para diagnóstico da infecção pelo HIV em adultos e crianças. 2018. Disponível em: http://www.aids.gov.br/pt-br/node/57787. Acessado em:29 de outubro de 2021.

5. FEITOSA H, et al. Avaliação das oportunidades perdidas no controle da transm issão vertical do HIV em Rio Branco, Acre, Brasil. Revista Cadernos de Saúde Pública, 2021;37(3):1-14.

6. FERNANDES R, et al. O desafio da prevenção da transmissão vertical do HIV no Município de Campos dos Goytacazes, Rio de Janeiro, Brasil. Revista Caderno Saúde Pública, 2005;21(4):1153-1159. 
7. GONÇALVES T, et al. Prevenção combinada do HIV? Revisão sistemática de intervenções com mulheres de países de média e baixa renda. Revista Ciência \& Saúde Coletiva, 2020 25(5):1897-1912.

8. GONÇALVES JR. Como escrever um artigo de revisão de literatura. Revista JRG de estudos acadêmicos, $2019 ; 2$ (5): 29-55.

9. HOLZMANN A, et al. Prevenção da transmissão vertical do vírus HIV: avaliação da assistência hospitalar. Revista Brasileira de Enfermagem, 2020;73(3):1-9.

10. LANAL FC, LIMA AS. Avaliação da prevenção da transmissão vertical do HIV em Belo Horizonte, MG, Brasil. Revista Brasileira de Enfermagem, 2010;63(4):587-94.

11. LIMA ACMAC, et al. Tecnologias e práticas educativas para prevenção da transmissão vertical do HIV. Revista Brasileira de Enfermagem, 2018;71(4):1759-67.

12. MACÊDO V, et al. Avaliação das ações de prevenção da transmissão vertical do HIV e sífilis em maternidades públicas de quatro municípios do Nordeste brasileiro. Revista Caderno de Saúde Pública, 2009;25(8):1679-1692.

13. MENDES K, et al. Revisão integrativa: método de pesquisa para a incorporação de evidências na saúde e na enfermagem. Revista Texto \& Contexto em Enfermagem, 2008;17(4):758-64.

14. MIRANDA A, et al. Avaliação da cascata de cuidado na prevenção da transmissão vertical do HIV no Brasil. Revista de Caderno de Saúde Pública, 2016;32(9): 1-9.

15. NETO PIS, et al. Fatores associados à transmissão vertical do vírus da imunodeficiência humana entre pacientes acompanhados em serviço especializado. Revista de Patologia do Tocantins, 2021;8(3): 100 -105.

16. ORGANIZAÇÃO MUNDIAL DA SAÚDE(OMS). HIV country profile.2019. Disponível em: https://cfs.hivci.org/countryfactsheet.html. Acessado em:30 de outubro de 2021.

17. PRADO T, et al. Factors associated with maternal-child transmission of HIV-1 in southeastern Brazil: a retrospective study. AIDS and Behavior. National Library of Medicine, 2018;22: 92-98.

18. REMERA E, et al. Towards elimination of mother-to-child transmission of HIV in Rwanda: a nested case-control study of risk factors for transmission. BMC Pregnancy and Childbirth. 2021;21(339):1-8.

19. SIQUEIRA $P$, et al. Análise hierarquizada dos determinantes da transmissão vertical do HIV: um estudo de casocontrole. Revista Brasileira de Saúde Materno Infantil, 2020; 20(4):997-1007.

20. SILVA S, et al. Rede de apoio a mulheres com HIV na prevenção da transmissão vertical: revisão integrativa. Revista Mineira de Enfermagem (REME), 2015;19(2): 225-231.

21. TRINDADE L, et al. Infecção por HIV em gestantes e os desafios para o cuidado pré-natal. Revista Brasileira de Enfermagem, 2021;74(4):1-7.

22. VASCONCELOS C, et al. Medidas de prevenção para transmissão vertical do HIV: acompanhamento de gestantes infectadas e crianças expostas. Revista Brasileira de Saúde Materno Infantil, 2021;21(1):217-225. 